Please send trade news information and illustrations to Arveen Bajaj at the $B D J$, Nature Publishing Group, The Macmillan Building, 4-6 Crinan Street, London N1 9XW.

Trade news is provided as a service to readers using text and images from the manufacturer, supplier or distributor and does not imply endorsement by the BDJ. Normal and prudent research should be exercised before purchase or use of any product mentioned.

\title{
Smart suction system
}

\section{New aesthetic concept for crowns and bridges}

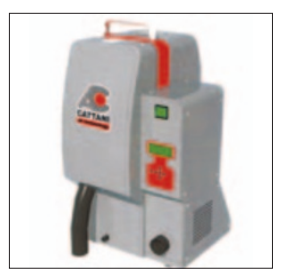

Until the launch of the new Turbo-Smart suction system it had previously been the accepted industry practice not to change a surgery from wetline to dry-line or vice versa because of the totally different vacuum characteristics. Cattani is now challenging this situation with amazing results in both wet-line and dry-line conversions thanks to Turbo-Smart. By providing high vacuum and high flow it can replace any wet or dry system with no noticeable drop in vacuum no matter what the demand, proving that Turbo-Smart is a truly universal aspirator. Dry line systems can be replaced easily as they normally have existing switch wires to operate the system remotely. Turbo-Smart uses no water so type 'A' airgaps and expensive water bills are a thing of the past. Turbo-Smart can use the existing suction pipe work as small as $32 \mathrm{~mm}$ and is compatible with all manufacturers' dental equipment. Turbo-Smart is also supplied complete with a new amalgam separation system that is the first to be certified across a variable flow range. For more information contact Cattani Esam UK Ltd on 01527877 997 or by e-mail on info@cattaniesam.co.uk. Reader response number 51

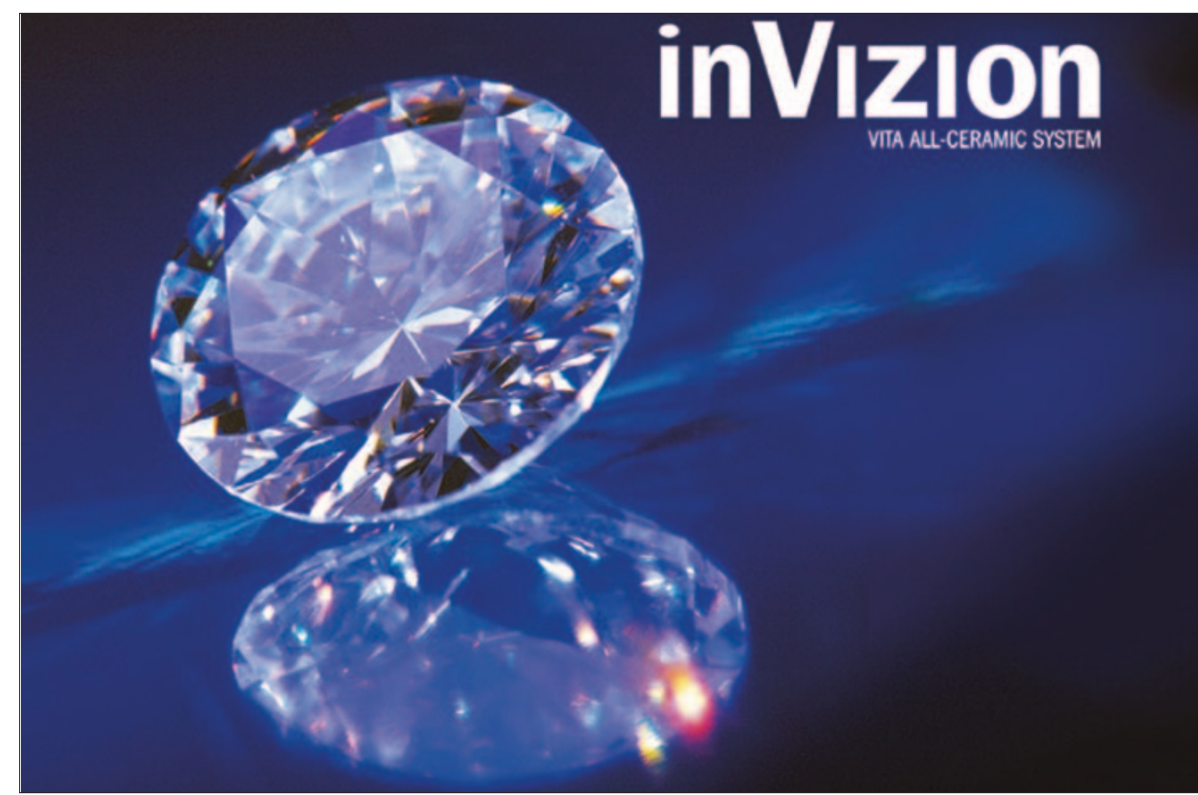

Yttrium-stabilised zirconia, the core of inVizion all-ceramic restorations offers high flexural strength (900+Mpa for inVizion frameworks). Milled using inLab's CAD/CAM system with oxide blocks, restorations are more accurately and efficiently produced, ensuring superb strength, marginal fit and aesthetics. Add to this Vita's VM9 fine structure porcelain for increased wear and optimal aesthetic results and inVizion is set for success. inVizion has more than seven years of successful restorations behind it, giving confidence and assurance for the clinician, technician and most importantly, the patient, proven by the growing take-up of this new generation of all-ceramic restorations. For more information and a list of participating laboratories call Panadent on 01689881788.

Reader response number 50

\section{Paint on tooth whitening system}

Many patients do not have enough time or patience to whiten their teeth using take home tooth whiteners. They may not be able to afford in-office whitening so the Pola Paint system is their next best option. Pola Paint is a fluoride releasing, mint flavoured, paint-on tooth whitening gel. With Pola Paint, there is no need for trays to be made. Patients simply purchase a kit from you and do the work themselves. Your patients can apply Pola Paint whenever they wish at anytime during the day or night. The low viscosity fast drying gel enables a film to form on the tooth surface with minimal drying time. Patients can choose to whiten one single tooth or their complete smile. Pola Paint is a great touch up procedure for patients who have already whitened their teeth before. Pola Paint is the economical first step to encouraging your patients to whiten their teeth. For further information, please contact SDI Limited: www.sdi.com.au, UK: 0080002255734.

Reader response number 52

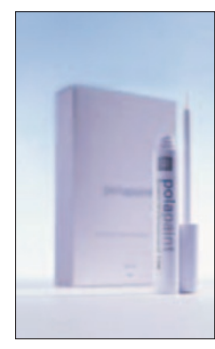

\section{The ultimate LED light}

Radii Plus brings new standards to LED curing lights. With an extremely high intensity of $1500 \mathrm{~mW} / \mathrm{cm}^{2}$, it is the most powerful LED light available. Its lithium-ion battery gives 1,200 10-second cures between charges. The unique curing tip gives a 360 degrees option to whatever position is required. All LED energy is at the end of the tip. A choice of curing tips: regular, single bleach, orthodontic and shortly full arch bleaching - the regular comes with the unit, the others are available separately. The one touch on/off button is activated with a finger. A click of the button turns the ramp mode on or off. Radii Plus is an efficient curing light that cures materials containing camphorquinone at 468-470 nanometers wavelength. No noisy fan as minimal heat is emitted. Radii Plus is cordless. The slimline design allows access to difficult areas and weighs just $6.2 \mathrm{oz} / 177 \mathrm{~g}$. The smooth gloss finish and touch pad control allows for easy cleaning. Radii Plus has a fiveyear limited warranty - two years on battery.

Reader response number 53 

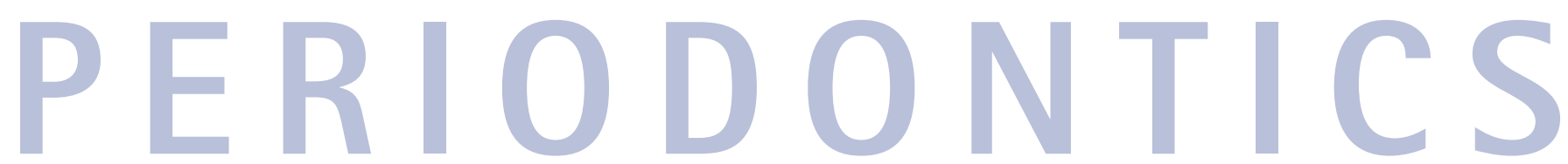

\section{A friendly periodontal probe}

The Periowise patented, multi-coloured Periodontal Probe is easy to read, gentle on tissue and safe to use around implant fixtures. Clear, well-defined markings in green and red give high visibility against tooth substance and soft tissue and ensure accurate pocket depth readings. A choice of 3-57-10 mm or 3-6-9-12 mm markings provide for individual preferences. The flexible tip gives excellent tactile sense and reduces the risk of tissue trauma or damage to implant fixtures. Made from an autoclavable polymeric material which can also be ultrasonically cleaned, Periowise is supplied in packs of three or six and is available from all major dental dealers. Periowise eliminates the most frustrating part of periodontal probing: poor readability. At a glance, you can quickly determine the depth of a pocket and make the appropriate diagnosis. Now it is easier than ever to diagnose periodontal disease, maintain proper records and ensure optimal treatment for your patients. For more information on Periowise, visit the website www.periowise.com with active demonstrations or contact: Myerson Ltd tel: 0208863 9044, fax: 02088613091 or e-mail:info@myersontooth.co.uk.

Reader response number 55

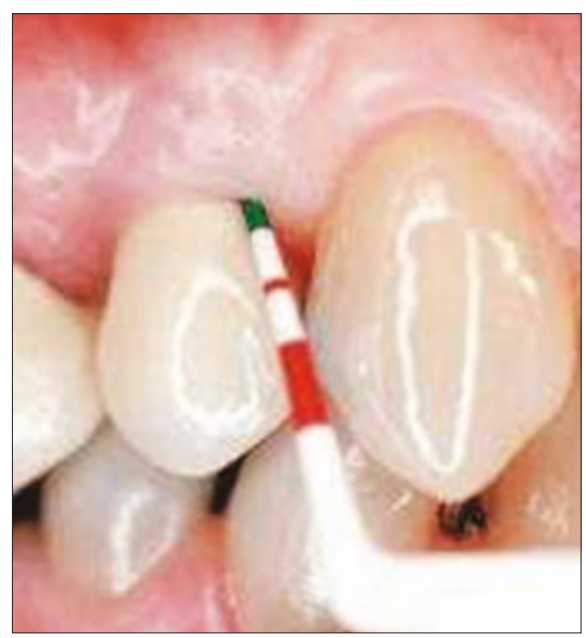

\section{Saliva testing}

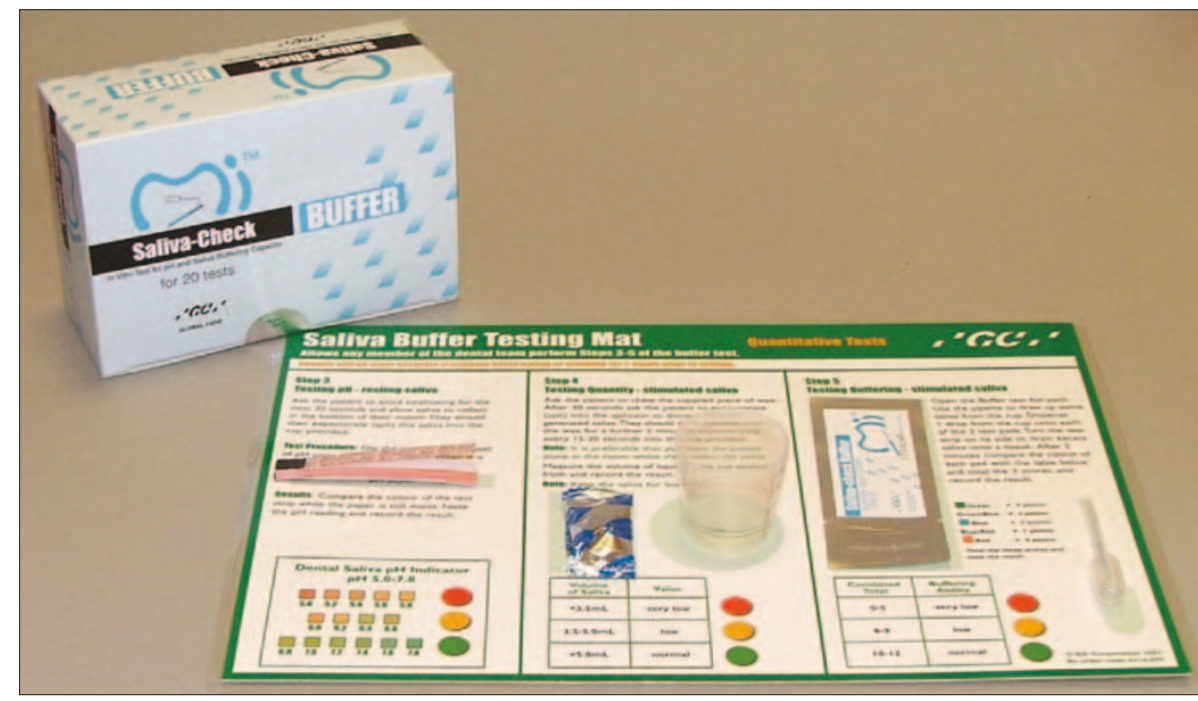

It is well known that saliva protects teeth from demineralisation. When a patient presents with sensitivity, caries or eroded lesions a solution can be found to correct or control these problems when it has been determined why the saliva is not adequately protecting the teeth. Once the problem has been recognised you are able to implement an appropriate prevention and remineralisation programme to rebalance the oral environment, helping to prevent further effects of demineralisation. GC's Saliva Testing kit is designed to test the saliva at both resting and stimulated states, as the characteristics of these forms of saliva are different. The GC Saliva Testing Kit has proved to be an effective tool in assisting with early detection of the condition of the oral environment. Your diagnostics will be greatly enhanced in terms of early detection of oral problems with improved patient communication and motivation combined with an increased dental awareness of your patients. For further information please contact GC UK Ltd on 01908 218999, e-mail gcuk@btinternet.com or visit www.gceurope.com. Reader response number 54

\section{Light on the subject}

The Sirona scaler is an ideal air-powered prophylactic handpiece for removing plaque which is made easier with the addition of fibre optic illumination by a powerful ring light. The SIROAIR L has three different power settings that can be regulated by the built-in control on the handpiece to suit specific circumstances for the amount of plaque removal and cleaning capabilities. Fibre optic illumination is incorporated to provide optimum light in all areas, and six tips are available for using most scaling and polishing procedures. The SIROTIP changer ensures that all tips can be interchanged quickly and efficiently and can also be used as a protective cap during sterilisation. The SIROAIR L will fit quickly and easily to a coupling on the dental unit without the need for separate foot control and water supply and may be sterilised in an autoclave at up to $135^{\circ} \mathrm{C}$. For more details please contact Sirona Dental Systems Ltd: 08450715040.

Reader response number 56

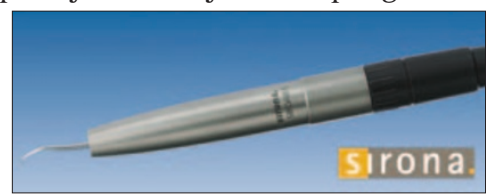




\section{PerioChip}

Patients no longer need to suffer the ill effects of periodontitis now that the highly effective PerioChip is available from dental suppliers across the UK. As the only locally delivered, slow release, non-antibiotic antimicrobial, PerioChip has become an integral part of the treatment of periodontal cases. PerioChip (2.5mg chlorhexidine), the UK market leader in adjunct therapies, is proven to substantially reduce periodontal pocket depth when used in conjunction with SRP, and has become the product of choice for many clinicians. Every dental practice can now benefit from the effects of PerioChip with the new Room Temperature PerioChip. This new format enables practice staff to store PerioChip without the need for refrigeration, allowing the product to be conveniently to hand during periodontal treatment. Room Temperature PerioChip retains all of the efficacy of the original formula but with added benefit of maintaining its rigidity during handling, making insertion of the chip even easier. For full details please call Dexcel Dental on 08000132333.

Reader response number 57

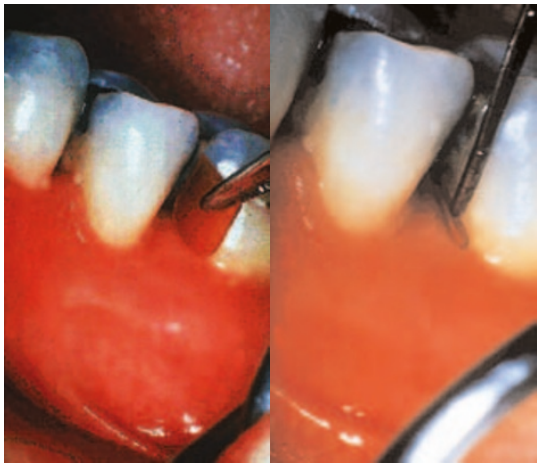

\section{Periostat (doxycycline 20mg)}

Periostat is one of the latest products to be introduced to the dental market for the treatment of chronic periodontitis. Periostat is an orally administered tablet containing a novel formulation of $23.08 \mathrm{mg}$ doxycycline hyclate. Designed to be taken twice a day as an adjunct to scaling and root planing (SRP), Periostat increases clinical attachment level gain and reduces probing depths in patients with chronic periodontitis. Periodontitis is characterised by periods of quiescence and unpredictable episodes of exacerbation. The underlying risk fac-

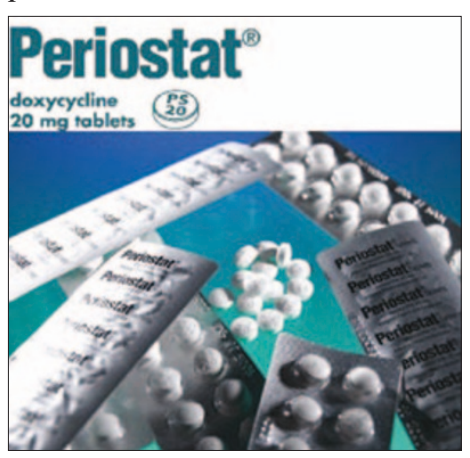
tors amplify tissue-destructive enzymes, resulting in disease progression that may manifest itself as attachment loss, bone loss and, in severe cases, tooth loss. The duration of treatment with Periostat, a prescription only medicine, will depend on the individual case but is recommended to be at least three months, and its use is approved for up to nine months to suppress the destructive collagenase enzymes and help stabilise the periodontium. Clinical evidence shows that Periostat produces clinically and statistically significant increases in attachment level gains as well as pocket depth reduction, in patients with moderate to severe periodontitis. Periostat is not intended to eliminate the need for clinical interventions or procedures that reduce the bacterial load in the periodontal pocket. Periostat is an adjunctive therapy, and is the only approved product formulated specifically to suppress the tissue destroying enzymes primarily responsible for the breakdown of the periodontium. To order or for further information on Periostat call Oraldent on 01480 862080/862084.

Reader response number 58

\section{Glass fibre reinforcement for chairside splints}

Minerva Dental Ltd are UK Distributors of everStickPerio, the pre-impregnated glass fibre system specifically designed for all splinting indications including periodontal and post traumatic splints. Cured directly onto compromised teeth, it creates a strong but suitably elastic long-term splint that can be easily removed when no longer needed. everStickPerio is a semi-manufactured product consisting of unidirectional glass fibres and a polymer/resin gel matrix for reinforcing dental composites. The first splinting material to meet all the demands for splinting, it is durable, easy to maintain and use. Simply measure the amount of fibre material needed, place it in position and light cure. Unlike other fibre materials, there is no fraying of fibres and it can be easily cut after curing. The material bonds well and reliably to teeth and is easy to maintain. Metal-free and transparent, an everStickPerio splint is aesthetically pleasing and patient-friendly. For further information please ask your local Minerva representative or telephone 02920490504.

Reader response number 59

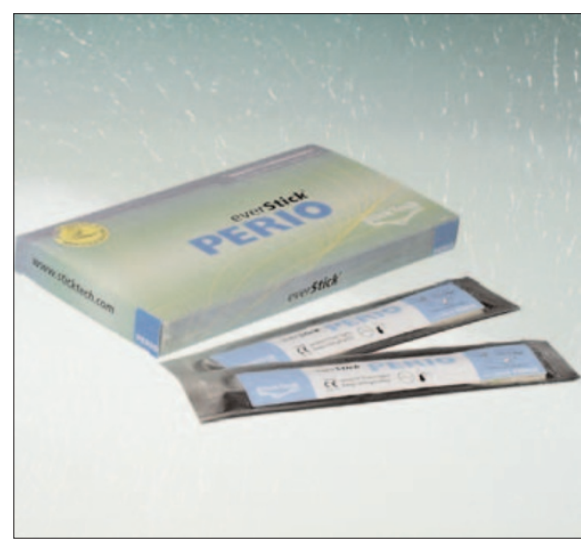

\section{Easy extractions with less trauma and bone loss}

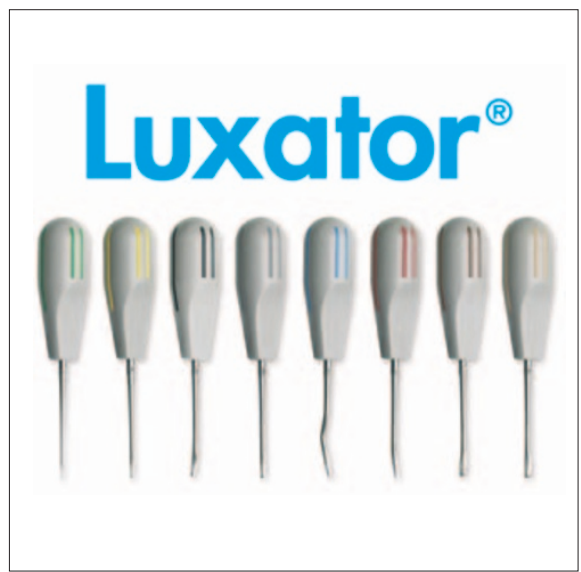

The SDI Directa Original Luxator is a time proven alternative to forceps extractions. It is a specially designed periodontal ligament knife with a fine tapering blade that compresses the alveolar bone, cuts the membrane and gently eases the tooth from it's socket. The whole operation is performed with the minimum of tissue damage, healing is quicker and the operation is less distressing both for the patient and surgical team alike. There is also less risk of post-operative pain, swelling and infection. The SDI Directa Original Luxator was invented and designed by a dentist to make extractions as trauma free as possible. He developed subtleties in the design that only a practising dentist would appreciate and it is for this reason that SDI Directa's Original Luxators are discernibly different.

SDI Directa Original Luxators are available in seven patterns. They can be purchased individually or in kits of 4 or 7 different patterns. Competitively priced they are included within Trycare's Catalogue, which is packed with good ideas, innovations and obscurities. For a free copy telephone 01274881044 or email mail@trycare.co.uk.

Reader response number 60 